\title{
Metatitanic Acid and Titania Pseudomorphs after Titanyl Sulfates
}

Mariana Klementovái,2, Monika Motlochová ${ }^{1,3}$, Jaroslav Boháček ${ }^{1}$, Jaroslav Kupčík ${ }^{1}$, Lukáš Palatinus ${ }^{2}$, Eva Pližingrová ${ }^{1}$, Lórant Szatmáry ${ }^{4}$, and Jan Šubrt ${ }^{1}$

1. Institute of Inorganic Chemistry of the CAS, v.v.i., CZ-250 68 Husinec- ̌̌ež, Czech Republic

2. Institute of Physics of the CAS, v.v.i., CZ-182 21 Prague, Czech Republic

3. Dpt. of Chemistry, Faculty of Science, University of Ostrava, CZ-701 03 Ostrava, Czech Republic

4. ÚJV Řež, a.s., Hlavní 130, CZ-250 68 Husinec-Řež, Czech Republic

One-dimensional (1D) nanostructured inorganic materials (nanowires, nanorods, or nanotubes) are interesting from various aspects. Such structures can be considered as building blocks for sensors, electronics, photonics, and bioelectronics applications. Their potential relies on the subtle control of their physical properties, which are based on their atomic scale structures, and their 1D morphology, i.e., their length and diameter dimensions at the nano- and microscale. By controlling these parameters, a variety of chemical and physical properties can be tailored [1,2].

The crystals of titanyl sulfate when immersed in aqueous ammonia at a temperature of about $0{ }^{\circ} \mathrm{C}$ provide solid residue composed of particles, whose shape and dimensions correspond perfectly to the particle morphology of the initial titanyl sulfate with composition matching that of metatitanic acid; i.e., the products of the reaction form pseudomorphs of metatitanic acid after titanyl sulfate. On annealing, the material transforms above $400{ }^{\circ} \mathrm{C}$ to anatase and subsequently above $\sim 1100{ }^{\circ} \mathrm{C}$ to rutile while perfectly maintaining the size and shape of the original particles.

Particle shape of the two starting materials (TSDand TSM) is distinctly different (Figure 1). Sample TSD consists of regular rod-like crystals with the size of about $10-15 \times 2 \mu \mathrm{m}$, whereas sample TSM is formed by aggregates of isometric crystals with broad size distribution. XRD patterns show that sample TSM corresponds to titanyl sulfate monohydrate $\left(\mathrm{TiOSO}_{4} \cdot \mathrm{H}_{2} \mathrm{O}\right)$ with a known structure while sample TSD consists of titanyl sulfate dihydrate $\left(\mathrm{TiOSO}_{4} \cdot 2 \mathrm{H}_{2} \mathrm{O}\right)$ of which the structure has not been determined yet [3]. As a part of this study, we solved the structure of titanyl sulfate dihydrate using dynamical refinement of precession electron diffraction tomography data [4].

The particle shape of TSD and TSM samples is determined by the atomic structure of the corresponding TS (Figure 1). The rod-like shape of TSD sample is the result of $1 \mathrm{D}$ morphology of $\left(\mathrm{TiO}_{5}\right)_{\mathrm{n}}$ helices mutually bound only by weak H-bonds in the structure of TSD. On the contrary, TSM forms a 3D framework connected through $\mathrm{Ti}-\mathrm{O}$ and $\mathrm{S}-\mathrm{O}$ bonds, while $\mathrm{H}_{2} \mathrm{O}$ molecules only fill the small channels in the structure. TSM sample therefore occurs as isometric crystals.

In both structures, the chains or helices formed by $\mathrm{TiO}_{6}$ corner-sharing octahedra are spaced with sulfate ions and water molecules. Although such structure cannot guarantee formation of pseudomorphs, it is a prerequisite for it. Given that during the reaction with the ammonia solution the morphology of the starting titanyl sulfate dihydrate is fully maintained, it can be assumed that during this reaction leaching of sulfate anions and their replacement with $\mathrm{OH}-$ anions take place. From the structural point, the replacement of sulfate by $\mathrm{OH}-$ anions does not cause a collapse of the structure as the newly bonded $\mathrm{OH}$-groups repel one another. When the structure loses the sulfate ions holding the $\left(\mathrm{TiO}_{6}\right)_{\mathrm{n}}$ chains/helices in shape, the helices of corner sharing octahedra most likely stretch out a little bit when 
repelled by $\mathrm{H}-\mathrm{H}$ interaction resulting in polymer-like chains of $\mathrm{TiO}_{6}$ octahedra similar for both samples, and characteristic of the amorphous metatitanic acid.

Since the size and morphology of the hydrated titanyl sulfate particles can be varied within wide limits by the conditions of its crystallization [3], the described method opens a new pathway to obtain particles of various titanium oxide compounds of desired shape and size. It has also been shown that the material has excellent sorption properties for radioactive isotopes.

\section{References:}

[1] R.K. Joshi and J.J. Schneider, Chem. Soc. Rev. 41 (2012), p.5285.

[2] H.S. Kim, S.-W. Jung, S.K. Yang, K.S. Ahn, S.H. Kang, Mater. Lett. 111 (2013) p. 47.

[3] English, P. M. Structural Studies of Titanyl and Zirconyl Sulphate Hydrates; Curtin University of Technology, 2011.

[4] L. Palatinus, V. Petricek, C.A. Correa, Acta Crystallogr., Sect. A: Found. Adv.71 (2015) p. 235. [5] The authors acknowledge funding from the Technological agency of the Czech Republic (Project No. TH02020110).
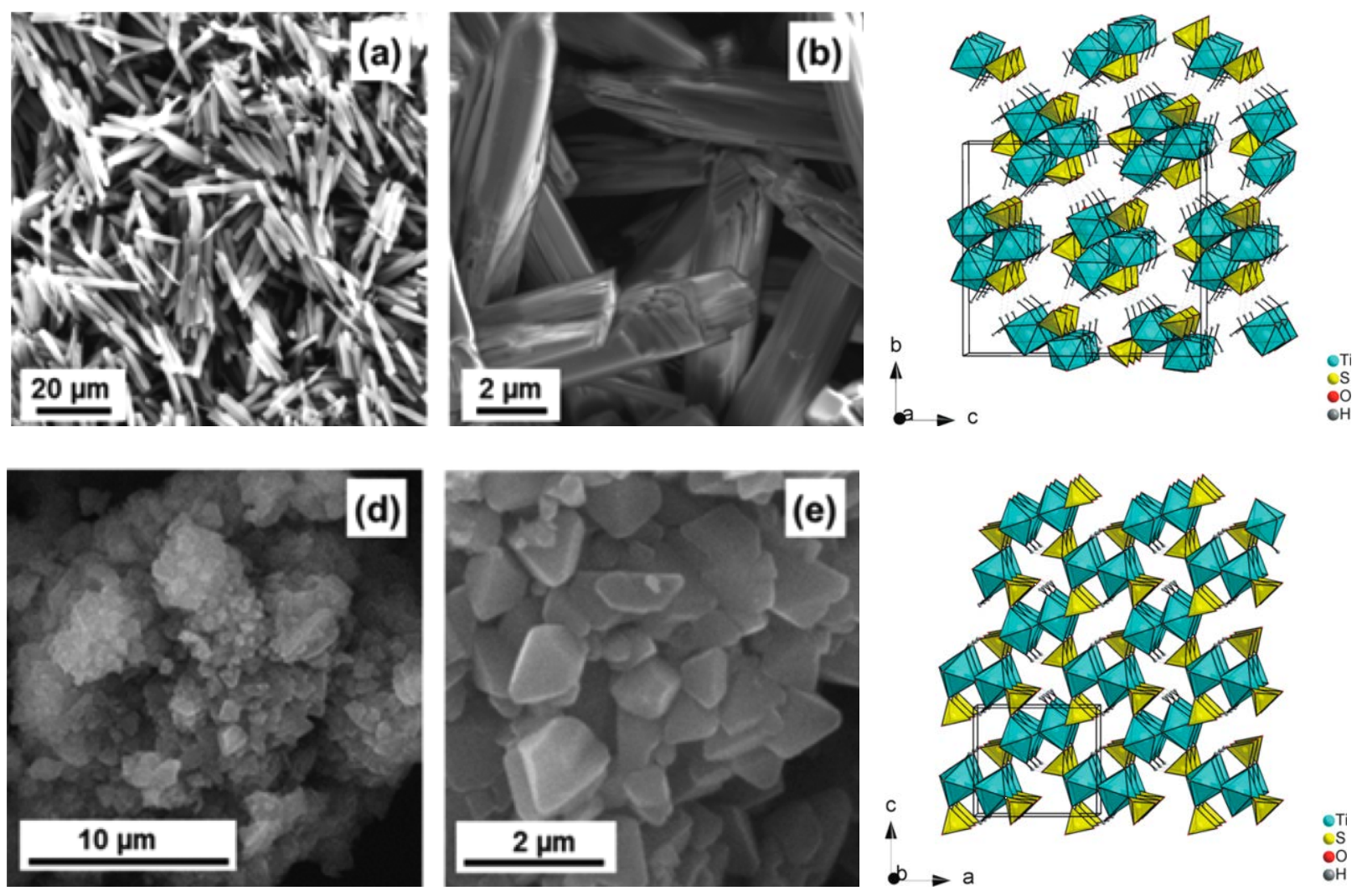

Figure 1. Metatitanic acid pseudomorphs: after titanyl sulfate dihydrate (a,b), structure of titanyl sulfate dihydrate (c), after titanyl sulfate monohydrate (d,e), structure of titanyl sulfate monohydrate (f). 